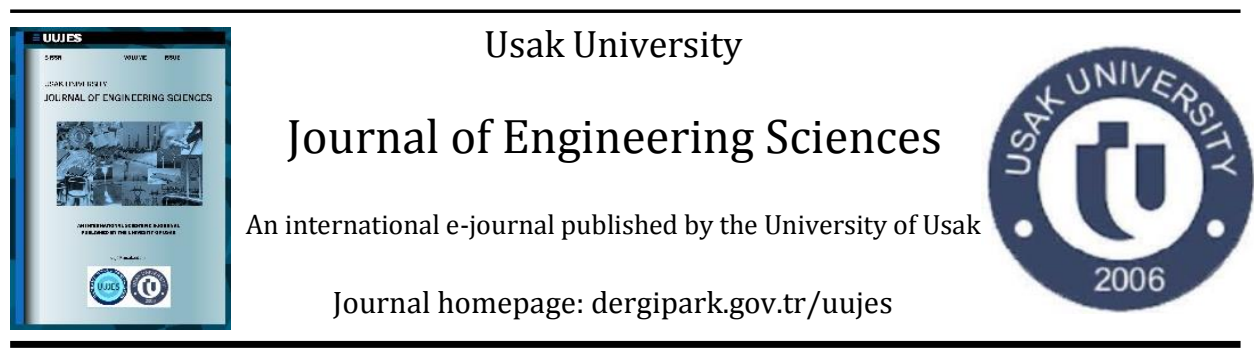

Research article

\title{
EFFECTS OF FABRIC COMPOSITION AND CONSTRUCTION ON THE PERFORMANCE PROPERTIES OF THE WORSTED FABRICS
}

\author{
Duygu Yavuzkasap Ayakta1, Sezin Celikkiran'1, Eren Oner²* \\ ${ }^{1} R \&$ D Center, Yünsa Worsted \& Woolen Production and Training Co, Tekirdag, Turkey \\ ${ }^{2}$ Department of Textile Engineering, Usak University, Usak, TURKEY
}

Received: 22 Sep 2020

Revised: 3 Dec $2020 \quad$ Accepted: 8 Dec 2020
Handling Co-Editor: Fulya Yilmaz

Online available: 28 Dec 2020

\begin{abstract}
The scope of current study is to research the influences of composition of weft and warp yarns and constitutive characteristics of fabric such as weft density and weave type on air permeability, wicking, tensile strength, breaking elongation of the worsted fabrics. For this purpose, 27 types worsted fabric samples with three different weft density, three different weave pattern and three different raw material composition were produced. The physical qualities of worsted fabrics were determined by appropriate measurements. The impact of fabric composition, weft density and weave design on performance properties of worsted fabrics were examined and analyzed with statistical analysis. According to the findings, it is understood that the air permeability values have decreased in the more compact weave types, wool fabrics have lower wicking heights among the samples, and the tensile strength values increase with increasing polyester ratio in the blend and weft density.
\end{abstract}

Keywords: Worsted fabric; performance test; fabric composition; fabric construction; wicking; breaking strength.

(C)2020 Usak University all rights reserved.

\section{Introduction}

Fabric quality is substantial to textile manufacturers, stylists, merchants and costumers by reason of it defines many properties as defect recovery, uniform construction, outlook and performance during manufacture and in the hands of consumers [1]. Whatever the economic power, pleasure and culture, the first effect in people who will take the fabric are appearance and handle of the fabrics. In order to improve the appearance and hand properties of the fabrics, fiber blending is made often in textile industry. The fiber blending is also made for improving usage features, physiology of clothing, cleaning *Corresponding author: Eren Oner E-mail: eren.oner@usak.edu.tr (ORCID: 0000-0003-2770-414X) 
properties and for productivity and economy [2]. Fabric structural parameters are another quite important determiner on clothing quality, usage performance, appearance features and fabric hand. Fabric construction parameters as weaving pattern and density are related to the various physical properties, such as the fabric permeability, moisture transport and performance. Therefore, the relationship between fabric quality properties and fabric composition and construction has still attracted important research attention. Similarly, the fiber blend and fabric structure of the worsted and blend fabrics widely used for suit garment for women and men are very important characteristics especially for business clothing industry and research area.

Several researchers studied the impacts of fiber characteristics and fabric structure on the hand and appearance features of worsted fabrics for suit garments in their theoretical and experimental researches. Kim et al. (2005) analyzed the surface-fiber profile on perceived hand of worsted fabrics, they found that larger amounts of surface fibers provide softer and warmer feeling of touch [3]. Behera and Mishra (2007) examined the light weight worsted suiting fabrics, their findings showed that wool and blends provide high transmission features [4]. In their another work on light weight worsted fabrics, they showed that the fabrics with a low crease recovery angle can tolerate a lower level of formability and have acceptable appearance [5]. Xu and Wang (2009), evaluated the shearing hysteresis of worsted fabrics, found that the increase of wool content, the shearing hysteresis tends to reduce [6]. Kim and Kim (2013), in their study on researching the mechanical properties of worsted fabrics, they determined that the high warp yarn tension during weaving makes the worsted fabric rigid [7]. Shahabj et al. (2013) examined the effects of weave structures and weft setting on the Poisson's ratio of worsted fabric, they showed that the Poisson's ratios were following the twill $2 / 2$, twill $3 / 1$ and hopsack $2 / 2$ from highest to lowest value [8]. Mert et al. (2014) investigated the impacts of calendering and milling process on thermal comfort and surface properties of suit fabrics, they found that air permeability, thickness and thermal resistance values were decreased, while thermal absorptivity values were increased after calendering process [9]. Farahani et al. (2018) studied the effect of sample weight, test speed, and sphere diameter on the bagging behavior of the worsted fabrics, and their findings indicated that sample weight and sphere diameter have a significant effect while test speed has no significant effect on the bagging parameters [10]. Ozdemir (2018) studied air permeability properties of worsted fabrics and the results showed that he structural properties of weaves such as the weave interlacing coefficient, the density of interlacing, arrangement of yarns are factors that increase the porosity of fabrics, so increase the air permeability [11]. Akcagun et al. (2019) investigated the thermal properties of wool and wool/PES fabric, they remarked that wool fibers with hydrophobic fibers, such as polyester, may bring positive effect on the thermal properties [12]. Mousazadegan and Ezazshahabi (2019) carried out to inspect the tensile behavior of worsted fabrics, their results showed that the tensile behavior of worsted fabrics affected by fabric weave structure and density [13].

However, there are few researches addressed physical, mechanical, and transfer properties measurement with systematically produced worsted fabrics, which had different controlled fiber blend, weave pattern and density levels. The present study is aimed at examining the air permeability, wicking, tensile strength and breaking elongation of the worsted fabrics with taking into account fiber blend, weave type and weft density, which are systematically changed. 


\section{Materials and Method}

\subsection{Material}

In this research 27 types of woven fabrics with three different weft density levels as loose, medium and tight, and three different weave patterns as plain, $2 / 1$ twill and $2 / 2$ twill produced from three types of composition of warp and weft yarns in 80/2 Nm which is $100 \%$ wool, $45-55 \%$ wool/polyester and $60-40 \%$ wool/polyester. All fabrics were systematically produced on Dornier HTV6/SD rapier machine with electronic Staubli dobby 2667. Each fabric type was woven at three different weft setting levels as loose-medium-tight $(20-25-30)$ at the same machine settings. The worsted fabrics produced for this study are shown in Table 1.

Table 1 The structural properties of the fabrics

\begin{tabular}{|c|c|c|c|c|}
\hline $\begin{array}{c}\text { Sample } \\
\text { Code }\end{array}$ & Composition of fabric & Weave & Weft Density & Weight $\left(\mathrm{g} / \mathrm{m}^{2}\right)$ \\
\hline 1 & $100 \%$ wool & Plain & 20 & 126 \\
\hline 2 & $100 \%$ wool & Plain & 25 & 141 \\
\hline 3 & $100 \%$ wool & Plain & 30 & 156 \\
\hline 4 & $100 \%$ wool & 2/1 Twill & 20 & 124 \\
\hline 5 & $100 \%$ wool & 2/1 Twill & 25 & 138 \\
\hline 6 & $100 \%$ wool & 2/1 Twill & 30 & 153 \\
\hline 7 & $100 \%$ wool & 2/2 Twill & 20 & 123 \\
\hline 8 & $100 \%$ wool & 2/2 Twill & 25 & 138 \\
\hline 9 & $100 \%$ wool & 2/2 Twill & 30 & 153 \\
\hline 10 & $60-40 \%$ wool/polyester & Plain & 20 & 122 \\
\hline 11 & $60-40 \%$ wool/polyester & Plain & 25 & 138 \\
\hline 12 & $60-40 \%$ wool/polyester & Plain & 30 & 156 \\
\hline 13 & $60-40 \%$ wool/polyester & 2/1 Twill & 20 & 119 \\
\hline 14 & $60-40 \%$ wool/polyester & 2/1 Twill & 25 & 135 \\
\hline 15 & $60-40 \%$ wool/polyester & 2/1 Twill & 30 & 150 \\
\hline 16 & $60-40 \%$ wool/polyester & 2/2 Twill & 20 & 119 \\
\hline 17 & $60-40 \%$ wool/polyester & 2/2 Twill & 25 & 134 \\
\hline 18 & $60-40 \%$ wool/polyester & 2/2 Twill & 30 & 151 \\
\hline 19 & $45-55 \%$ wool/polyester & Plain & 20 & 125 \\
\hline 20 & $45-55 \%$ wool/polyester & Plain & 25 & 140 \\
\hline 21 & $45-55 \%$ wool/polyester & Plain & 30 & 157 \\
\hline 22 & $45-55 \%$ wool/polyester & 2/1 Twill & 20 & 124 \\
\hline 23 & $45-55 \%$ wool/polyester & 2/1 Twill & 25 & 137 \\
\hline 24 & $45-55 \%$ wool/polyester & 2/1 Twill & 30 & 150 \\
\hline 25 & $45-55 \%$ wool/polyester & 2/2 Twill & 20 & 122 \\
\hline 26 & $45-55 \%$ wool/polyester & 2/2 Twill & 25 & 138 \\
\hline 27 & $45-55 \%$ wool/polyester & 2/2 Twill & 30 & 152 \\
\hline
\end{tabular}




\subsection{Method}

Air permeability, wicking, tensile strength and breaking elongation measurements have been made on the fabrics according to relevant standards. The fabric samples have been kept at $20 \pm 2^{\circ} \mathrm{C}, 65 \pm 5 \% \mathrm{RH}$ conditions for 24 hours. The findings of the measurements have been analyzed with ANOVA with Minitab 17 statistical packet program. 95\% confidence interval was used to assess level of significance.

While air permeability is defined as the ability of the air to pass through the fiber, yarn and fabric structure. It is the amount of air passing through unit pressure and unit area at a certain time. Air permeability of fabrics were tested in reference to ASTM D737-04. Textile material is put under the head of test device the way that it is not wrinkle. $5 \mathrm{~cm}^{2}$ experiment space is placed on the surface of circular fabric holder. The air vacuum system is run and the test is gone on until the pressure difference between two faces of the fabric reaches to $200 \mathrm{~Pa}$ by gradually increasing the air flow which is passed from inside of specific area of the sample. The air flow amount which is passed from inside of the fabric is recorded as $\mathrm{l} / \mathrm{m}^{2} / \mathrm{s}$. 10 tests were done by taking homogeny samples from side-middle-side areas of the fabrics. For comparisons, statistical analyses were done.

The liquid sweat formed in the body firstly causes the surface of the fabric to get wet, and subsequently, with the effect of capillary forces, the liquid sweat moves horizontally and vertically in the structure. Wicking is a determining parameter for the liquid to move through the fabric structure with the help of capillary forces. If the clothing becomes saturated from exertion the wicking ability is limited. Wicking of fabrics were tested in reference to Marks \& Spencer (M\&S) P 136 B standard, which is commonly used in the suits industry. Vertical wicking tests were conducted on the apparatus has been illustrated in Fig. 1. Five specimens were cut through the weft and warp directions in dimension of $200 \mathrm{~mm} \times 40 \mathrm{~mm}$. The fabric sample was hanged vertically with its bottom end immersed in a purified water. The bottom ends of the fabric samples were immersed vertically at a depth of $2 \mathrm{~mm}$ into the $50 \mathrm{ml}$ water. The maximum vertical rise of the water to the nearest $\mathrm{mm}$ was recorded after 3 minutes. Each sample was tested 3 times and averages were taken.

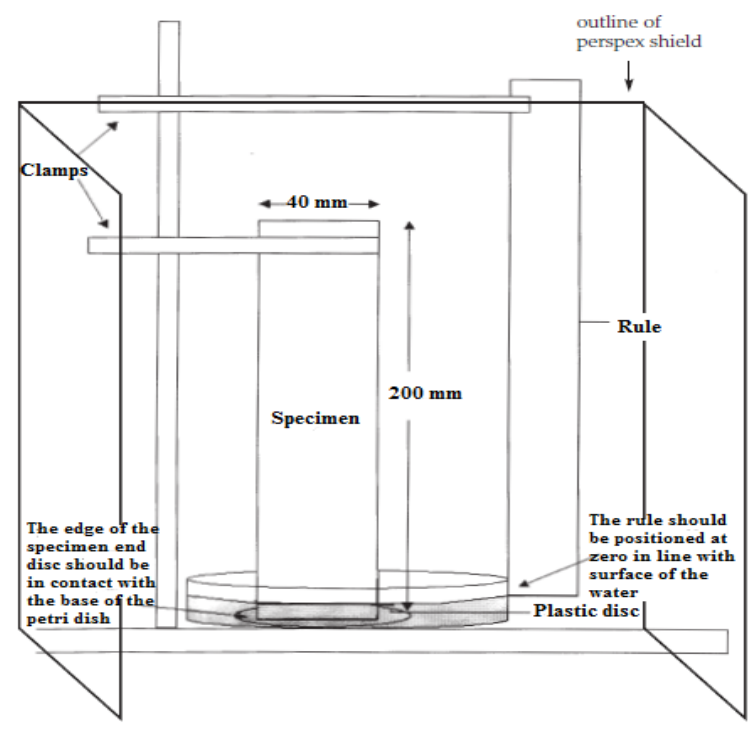

Fig. 1 Test equipment of wicking 
Tensile strength and breaking elongation properties of fabric samples have obtained by stripe method in accordance with ASTM D2256. The fabric samples have been pulled until break by Multipurpose Strength Tester, Zwick, at $100 \mathrm{~mm} / \mathrm{min}$. Measurement length has been selected as $200 \mathrm{~mm}$.

\section{Results and Discussion}

\subsection{Air permeability}

The measurement results of air permeability of fabric samples are shown in Fig. 2. The porosity, which is expressed as the total void volume in the fabric and is occurred due to the raw material, fabric geometry and yarn properties, directly affects the air permeability of the fabric. For this reason, when examining the effects of the parameters such as yarn structure, weave type, density and finish treatment on the air permeability, the changes in fabric porosity are observed. When air permeability measurement results are examined, it has been observed that the values decrease in the more compact weave types, where the pattern is covered more, and with increasing density due to the reduced porosity. This confirms the relationship between fabric porosity and air permeability. This observation is in agreement with data from Behera and Mishra (2007), who examined the worsted suited fabrics [4]. According to the obtained results, the highest air permeability values have been found for $2 / 2$ Twill $60-40 \%$ wool/polyester fabrics with medium weft density level. It is also observed that, the air permeability values decreased as the weft setting level increased. In terms of weaving pattern, it is seen that, the air permeability is found to be as $2 / 2$ Twill, $2 / 1$ Twill and Plain fabric structures from high to low, respectively. When the findings are evaluated in terms of fiber blend, it is seen that fabrics containing $60-40 \%$ wool-polyester have high air permeability values in general.

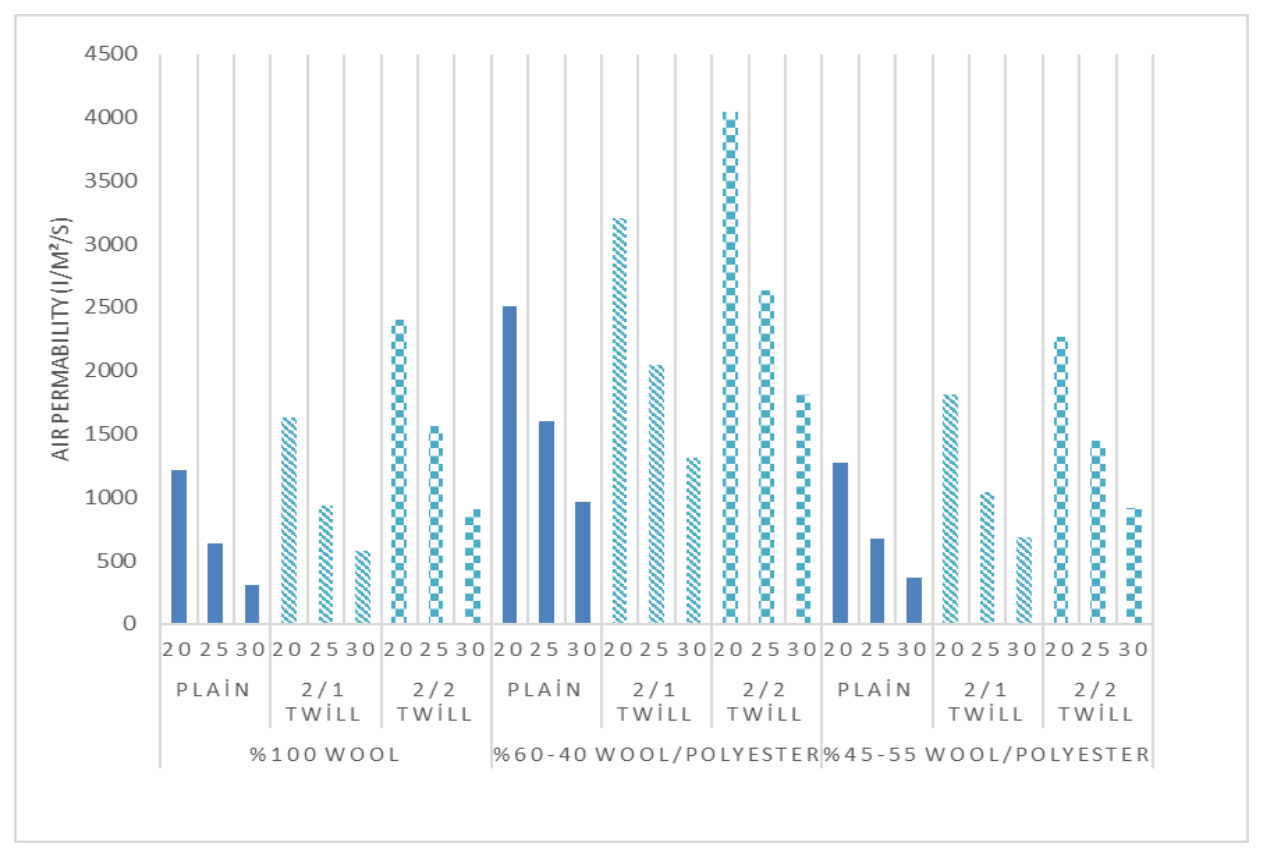

Fig. 2 The air permeability values of the fabrics 
Obtained air permeability results were analyzed statistically by the help of Minitab 17. It was verified that general linear model of air permeability had worked with 99,33\% precision level. Variance analyses of air permeability of fabrics are given at Table 2 .

Table 2 Results of analysis of variance for air permeability

\begin{tabular}{lcc}
\hline Source & F & P \\
\hline Composition & 2012.79 & $0.000^{*}$ \\
Weave & 1130.47 & $0.000^{*}$ \\
Weft Density & 2516.13 & $0.000^{*}$ \\
Composition*Weave & 18.42 & $0.000^{*}$ \\
Composition*Weft Density & 79.27 & $0.000^{*}$ \\
Weave*Weft Density & 35.82 & $0.000^{*}$ \\
Composition*Weave*Weft Density & 1.40 & 0.220 \\
\hline
\end{tabular}

*Statistically significant at $95 \%$ confidence level $(\mathrm{p}<0.05)$

The interaction effects of fabric composition, weave pattern and weft density on air permeability are also tested (Fig. 3). It is once again seen from Fig. 3 that air permeability gradually decreases with the increase of weft density. In terms of fabric composition, it is particularly attracting attention that $60 / 40 \%$ wool/polyester fabrics are separated from the group with high values. When evaluating in terms of weave type, it is again seen that the highest to lowest air permeability is $2 / 2$ Twill, $2 / 1$ Twill and Plain, respectively. It is understood that, as the number of intersections in weave type increased, air permeability decreased.

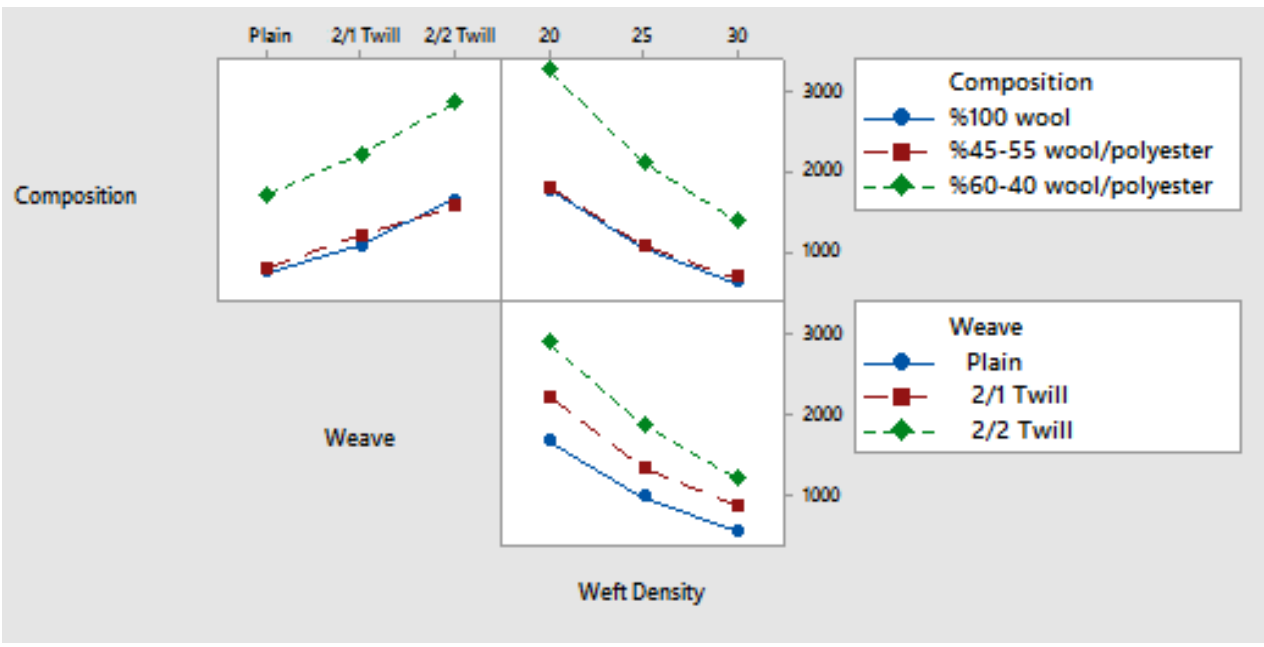

Fig. 3 Interaction plot of air permeability results

\subsection{Wicking}

The results of wicking measurement made on the fabric samples prepared in the weft and warp directions are presented in Fig. 4. According to results obtained, it is seen that $100 \%$ wool fabrics have the lowest wicking values among fabrics. Although wicking measurement is known as vertical absorption, actually it is the rise of liquid through the fabric vertically. Therefore, the capillary behavior and transport ability of fabric become 
more important than its absorbing capacity [14]. When viewed from this aspect, wool fibers absorb liquid and keep it in their structure, so that this condition decelerates the capillary transportation rate. In spite of that, polyester fibers have positive effect on wicking ability of fabric thanks to these fibers non-absorbing but capillary transporting structure. On the other hand, the measurement time for determining of wicking height was chosen 3 minutes according to M\&S standard, and this condition can be reason for low wicking values of the fabrics having more hydrophilic fibers.

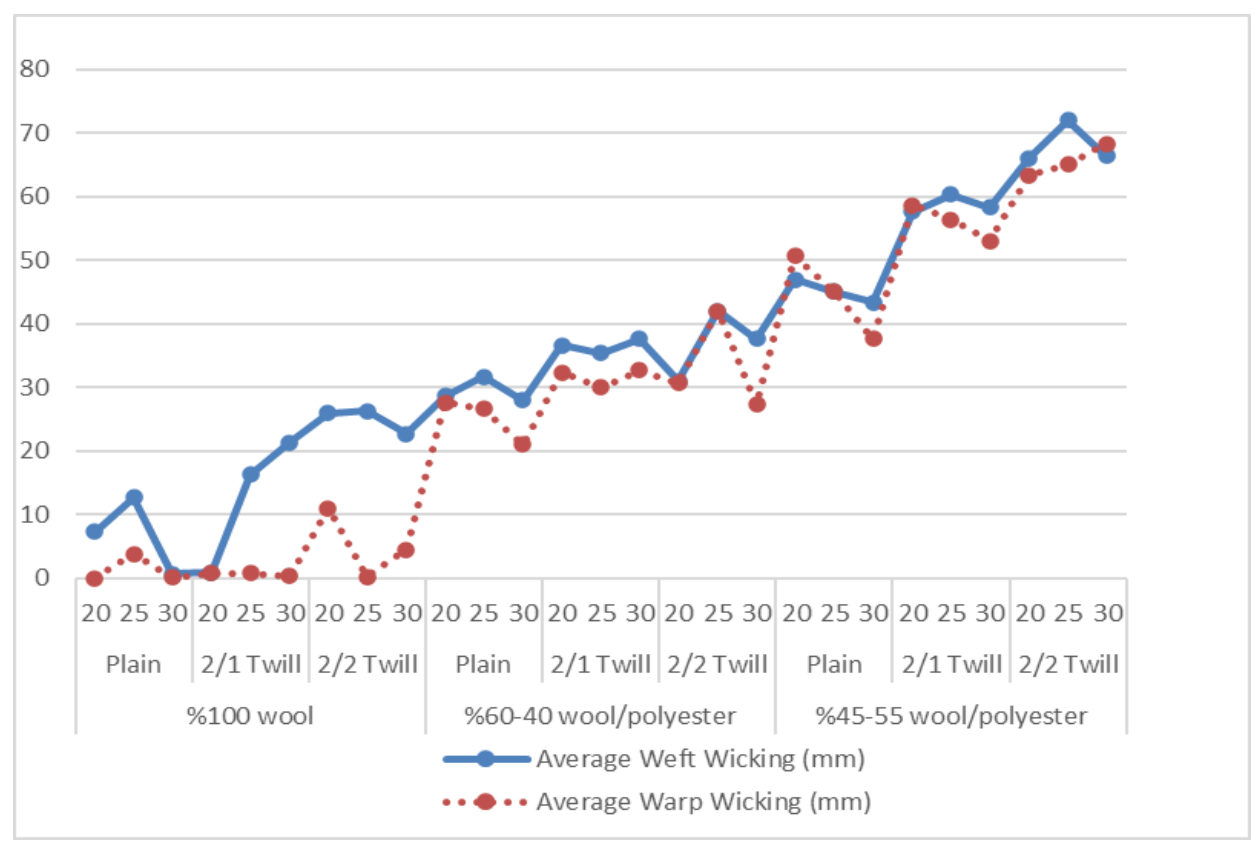

Fig. 4 The wicking of the fabrics for warp and weft direction

According to the results of ANOVA which has been performed for wicking along warp and weft directions separately are shown in Table 3. It was verified that general linear model of warp direction and weft direction had worked with $96.03 \%$ and $97.59 \%$ precision level respectively.

Table 3 Results of analysis of variance for wicking

\begin{tabular}{lcccc}
\hline \multirow{2}{*}{ Source } & \multicolumn{2}{c}{ Warp direction } & \multicolumn{2}{c}{ Weft direction } \\
& F & P & F & P \\
\hline Composition & 1102.46 & $0.000^{*}$ & 2209.96 & $0.000^{*}$ \\
Weave & 101.82 & $0.000^{*}$ & 321.24 & $0.000^{*}$ \\
Weft Density & 57.30 & $0.000^{*}$ & 79.96 & $0.000^{*}$ \\
Composition*Weave & 51.79 & $0.000^{*}$ & 155.26 & $0.000^{*}$ \\
Composition*Weft Density & 31.35 & $0.000^{*}$ & 34.76 & $0.000^{*}$ \\
Weave*Weft Density & 21.03 & $0.000^{*}$ & 45.70 & $0.000^{*}$ \\
Composition*Weave*Weft Density & 17.92 & $0.000^{*}$ & 33.32 & $0.000^{*}$ \\
\hline *Statistically significant at $95 \%$ confid
\end{tabular}


The results of interaction test applied to the warp and weft directions of the fabric samples are given in Fig. 5 and Fig. 6, respectively. As seen in both figures, the blend with the highest wicking value is $45-55 \%$ wool/polyester followed by $60-40 \%$ wool / polyester and the lowest is $100 \%$ wool. This reveals the difference between the water absorbing ability and capillary transport capacity of fibers. As wicking tests are based on the degree of leveling of the liquid reached, high values are obtained as the polyester ratio in the structure increases.

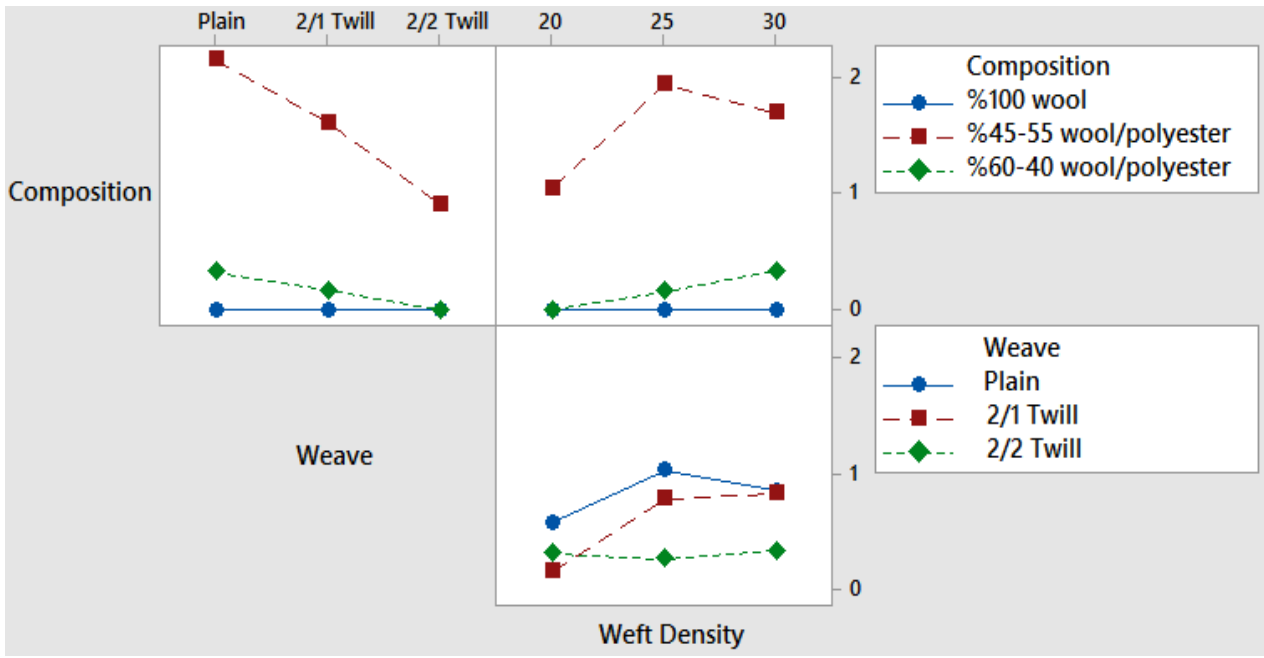

Fig. 5 Interaction plot of wicking for warp direction of fabrics

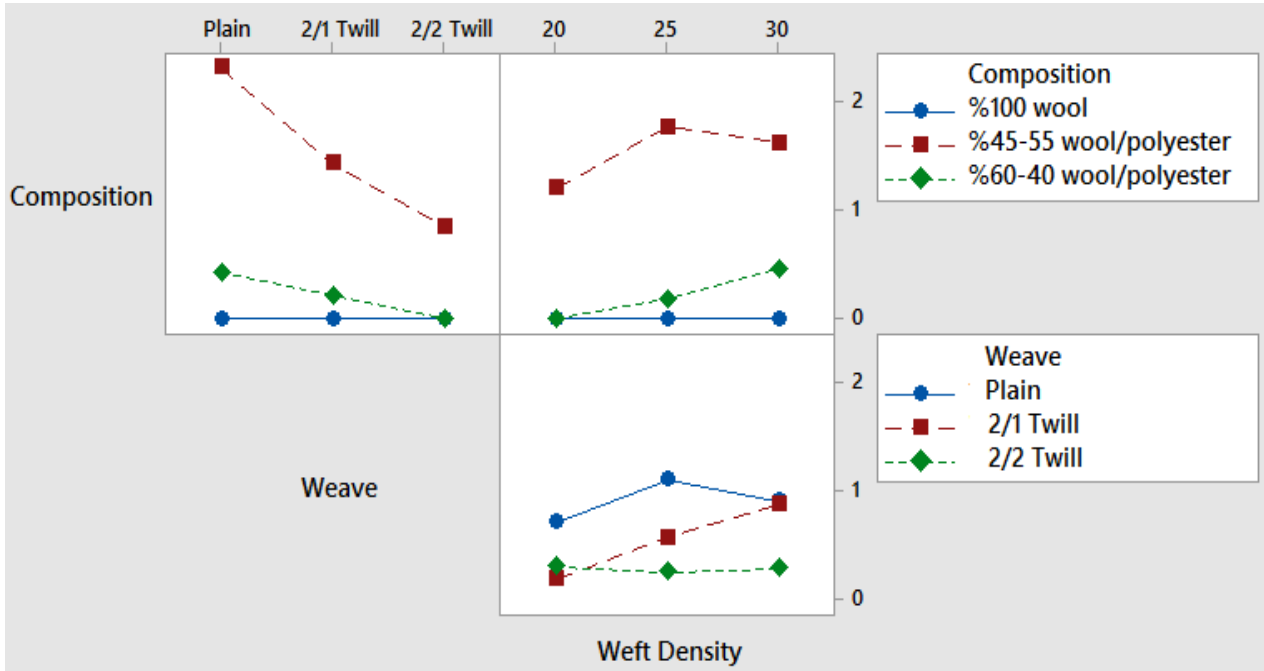

Fig. 6 Interaction plot of wicking for weft direction of fabrics

Besides, it has been determined that the highest to lowest wicking ability is Plain, $2 / 1$ Twill and 2/2 Twill, respectively. 


\subsection{Breaking strength}

Results of breaking strength test measurements of fabric samples in warp and weft directions are shown in Fig. 7. According to the findings, the lowest breaking strength values have been found at \%100 wool fabrics. Most natural and manufactured fibers have greater breaking strength than wool [15]. In spite of that, the incorporation of polyester fibers into the structure caused the higher breaking strength values, as expected. It has been observed that, the breaking strength in the weft direction increases as the weft density increases. The reason for an increase in the breaking strength value, could be the number of yarns per unit area increased with increasing setting.

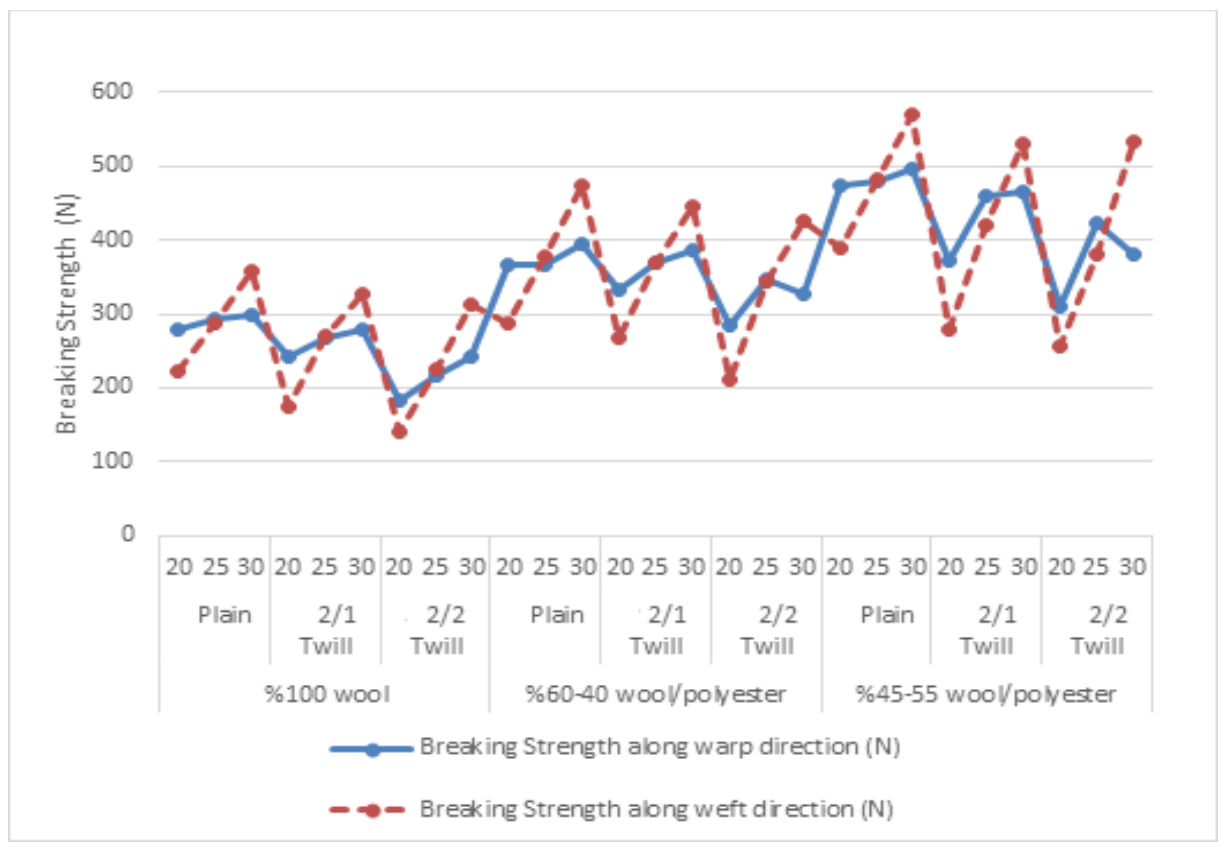

Fig. 7 The breaking strength of the fabrics along warp and weft direction

ANOVA results which have been conducted for tensile strength along warp and weft directions separately are seen in Table 4. It can be concluded that, the effects of composition of weft yarn, weave, weft density and involving weave of binary interactions that composition of weft yarn*Weave and Weave*Weft Density on tensile strength along warp directions are statistically significant at $95 \%$ confidence interval. Similarly, the effects of composition of weft yarn, weave, weft density and all of the binary interactions on tensile strength along weft directions are statistically significant $(\mathrm{p}<0.05)$. 
Table 4 Results of analysis of variance for breaking strength

\begin{tabular}{lcccc}
\hline \multirow{2}{*}{ Source } & \multicolumn{2}{c}{ Warp direction } & \multicolumn{2}{c}{ Weft direction } \\
& F & P & F & P \\
\hline Composition & 308.07 & $0.000^{*}$ & 384.16 & $0.000^{*}$ \\
Weave & 69.32 & $0.000^{*}$ & 63.11 & $0.000^{*}$ \\
Weft Density & 27.3 & $0.000^{*}$ & 502.16 & $0.000^{*}$ \\
Composition*Weave & 2.79 & $0.035^{*}$ & 3.64 & $0.011^{*}$ \\
Composition*Weft Density & 1.84 & 0.134 & 7.48 & $0.000^{*}$ \\
Weave*Weft Density & 3.91 & $0.007^{*}$ & 3.75 & $0.009^{*}$ \\
Composition*Weave*Weft Density & 0.97 & 0.473 & 1.07 & 0.398 \\
\hline *Statistically significant at 95\% confidence level $(\mathrm{p}<0.05)$ & & &
\end{tabular}

The interaction plots of breaking strength along warp and weft directions are presented in Fig. 8 and Fig. 9, respectively. As seen in the figures, 45-55\% wool/polyester fabrics have the highest breaking strength values, $60-40 \%$ wool/polyester have followed them, and $100 \%$ wool fabrics have the lowest values. It has also been revealed in different studies that polyester fibers increase the strength values of materials [16]. When evaluating in terms of type of weave, it is found that the highest breaking strength values are observed in Plain weave, followed by $2 / 1$ Twill and $2 / 2$ Twill respectively. In the cases where the number of intersections is more, the yarns support each other and fabric becomes a stronger structure, nevertheless increasing the number of steps has caused the fabric to have lower breaking strength values.

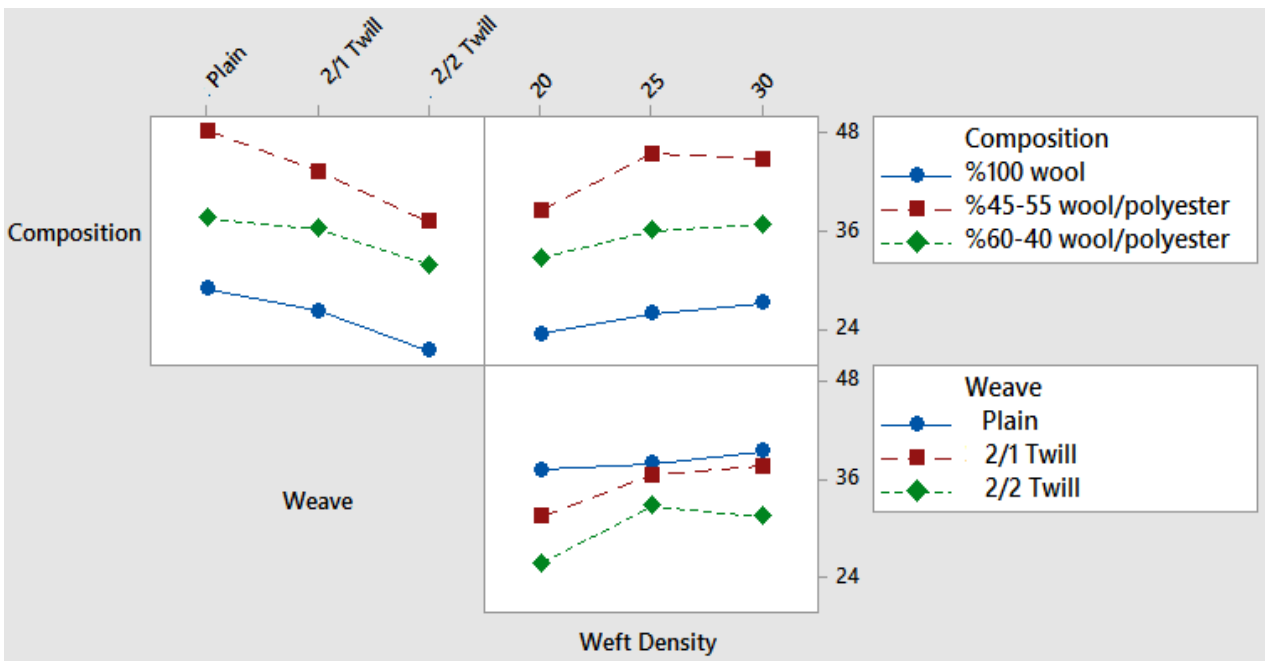

Fig. 8 Interaction plot of breaking strength for warp direction of fabrics 


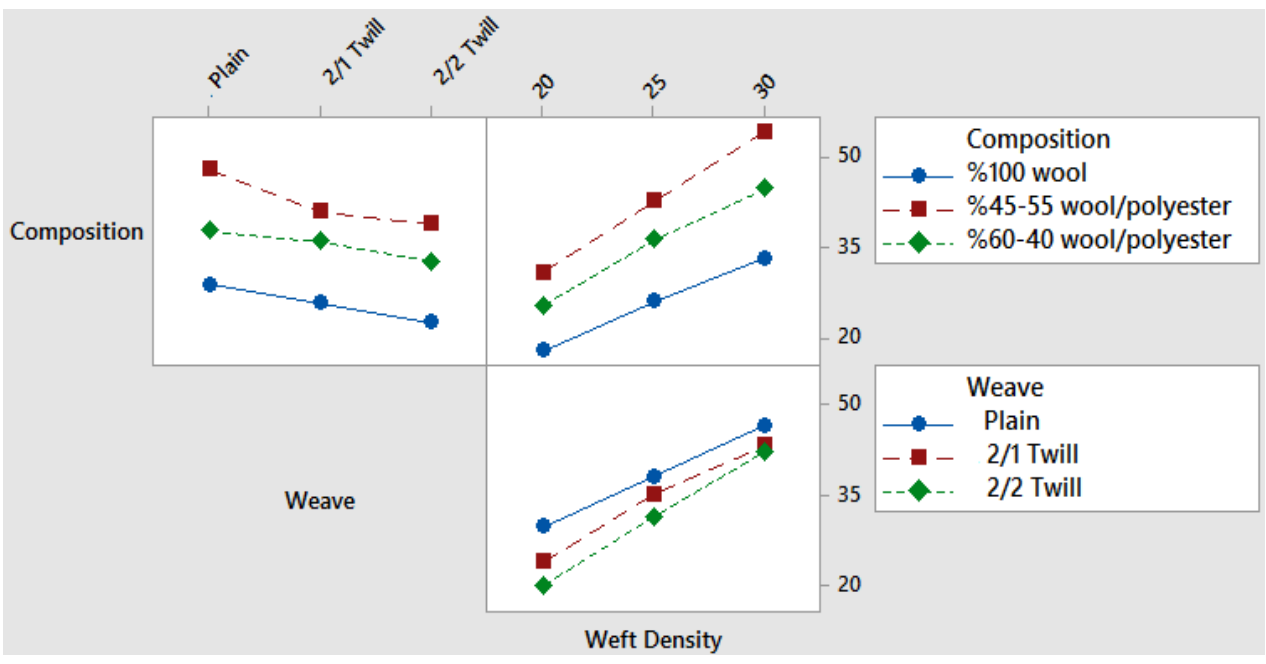

Fig. 9 Interaction plot of breaking strength for weft direction of fabrics

As seen in the interaction plot of breaking strength along weft yarns, the increase in the weft density increases the breaking strength values in the weft direction.

\subsection{Elongation}

The results of average elongation at break test of fabric samples are given in Fig. 10. It has been observed that, $100 \%$ wool fabrics have the highest elongation values among fabrics used in this study. Considering the elongation properties of polyester fibers, it is thought that other factors are more effective in the formation of this state than raw materials.

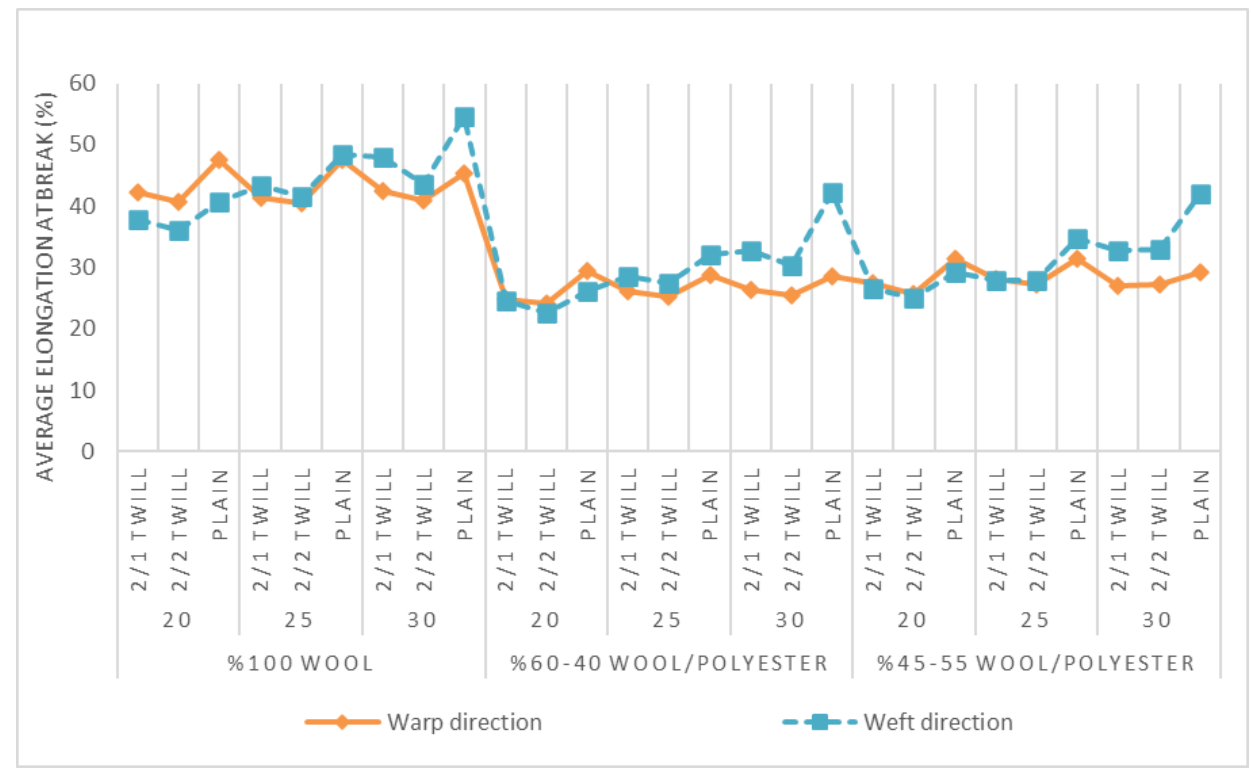

Fig. 10 The elongation at break of the fabrics for warp and weft direction 
Variance analysis results are given in Table 5. It can be seen that the effects of composition of weft yarn, weave, weft density and weave*weft density of binary interactions on elongation at break along weft and warp directions are statistically significant $(\mathrm{p}<0.05)$.

Table 5 Results of analysis of variance for elongation

\begin{tabular}{lcccc}
\hline \multirow{2}{*}{ Source } & \multicolumn{2}{c}{ Warp direction } & \multicolumn{2}{c}{ Weft direction } \\
& F & P & F & P \\
\hline Composition & 2730.44 & $0.000^{*}$ & 908.39 & $0.000^{*}$ \\
Weave & 198.81 & $0.000^{*}$ & 198.83 & $0.000^{*}$ \\
Weft Density & 1.94 & 0.153 & 377.89 & $0.000^{*}$ \\
Composition*Weave & 4.33 & 0.004 & 1.78 & 0.147 \\
Composition*Weft Density & 2.08 & 0.096 & 3.300 & $0.017^{*}$ \\
Weave*Weft Density & 6.20 & $0.000^{*}$ & 17.74 & $0.000^{*}$ \\
Composition*Weave*Weft Density & 1.13 & 0.36 & 1.34 & 0.245 \\
\hline${ }^{*}$ Statistilly sigificant
\end{tabular}

*Statistically significant at $95 \%$ confidence level $(\mathrm{p}<0.05)$

The interaction plots of elongation at break along warp and weft directions are presented in Fig. 11 and Fig. 12, respectively. It is seen that plain weave patterns have the highest elongation values among fabrics. When examining the effect of weft density, it is found that elongation values have increased with increasing weft density in elongation tests along weft direction.

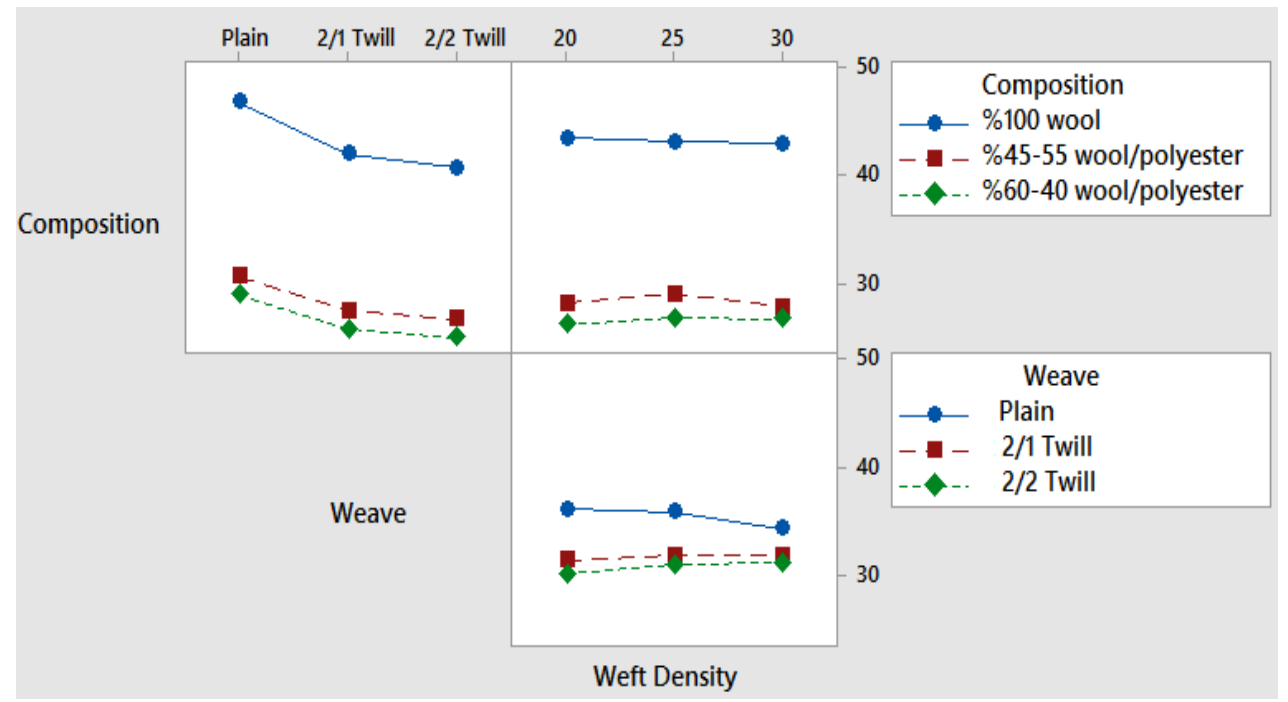

Fig. 11 Interaction plot of elongation for warp direction of fabrics 


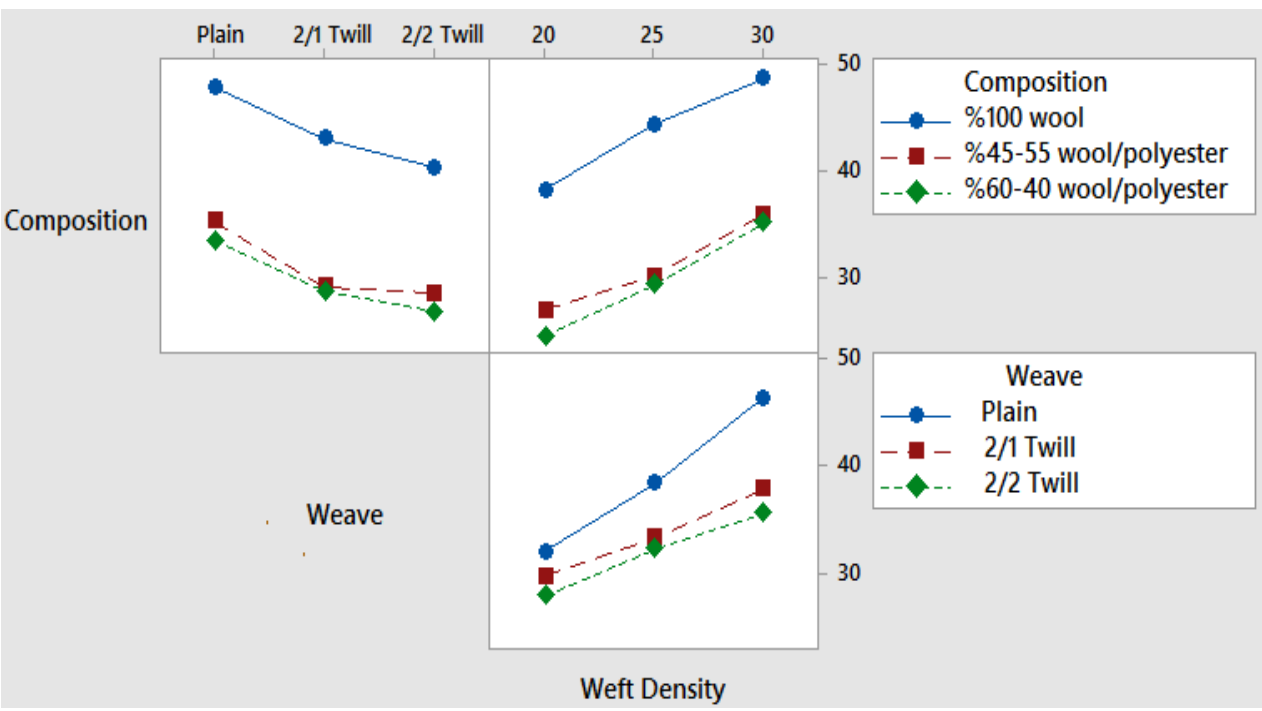

Fig. 12 Interaction plot of elongation for weft direction of fabrics

\section{Conclusion}

Wool garments are preferred by consumers for four seasons because of advantageous properties such as natural, biodegradable, renewable, warm feeling etc. of wool fibers. Thanks to these beneficial features, worsted fabrics are preferred by many employees to use both in the office environment and in external conditions. In these usage areas, performance properties such as breathability, wetness behavior, strength and elasticity of the worsted fabrics are being important according to clothing type and style. In the present work, the effects of fabric composition and construction on the performance properties of the worsted fabrics were investigated. In this context, air permeability, wicking ability, breaking strength and elongation properties of the worsted fabrics, which have three different weft density, three different weave pattern and three different raw material composition, are discussed.

As the results of air permeability measurements are considered, it has been concluded that the breathability of the fabrics decreases in the more compact weave types, where the pattern is covered more, and with increasing density due to the reduced porosity. In terms of raw material composition, it is seen that the air permeability values have decreased in the more compact weave types. According to the wicking results, it is understood that wool fibers have lower wicking heights among the fabrics, and this condition may be related to the capillary behavior and transport ability of fabric, which become more important than its absorbing capacity in terms of wicking. When breaking strength measurements are taken into consideration, it is found that breaking strength values of samples increase with increasing polyester ratio in the blend and weft density. Besides, the highest breaking strength value was observed in Plain weave, followed by $2 / 1$ Twill and 2/2 Twill respectively. Plain weave types have also the highest values for elongation measurements. Considering elongation results, $100 \%$ wool fabrics have the highest elongation values among fabrics used in this study. Considering the elongation results, it is found that elongation values have increased with increasing weft density in elongation tests along weft direction. 
This study has focused on the performance properties of the worsted fabrics in the suits industry, and the findings may be beneficial for researchers and wool garment industry. Based on the results obtained, it is understood that some other usage properties such as thermal comfort, wear and hand may be analyzed according to the usage purposes of the suit garments in the further studies.

\section{Acknowledgements}

The authors would like to thank Yünsa Worsted \& Woolen Production and Training Co. for their help in producing and testing of the samples.

\section{References}

1. Kadolph SJ, Langford AL. Textiles (9th Edition). Upper Saddle River, New Jersey: Prentice-Hall; 2002.

2. Song G. Improving comfort in clothing. Cambridge: Woodhead Publishing Limited; 2011.

3. Kim DO, Yoo S, Kim EA. Objective measures for perceived touch of worsted fabrics. International Journal of Industrial Ergonomics, 2005;35(12):1159-1169.

4. Behera BK, Mishra R. Comfort properties of non-conventional light weight worsted suiting fabrics. Indian Journal of Fibre \& Textile Research, 2007;32:7279.

5. Behera BK, Mishra R. Effect of crease behaviour, drape and formability on appearance of light weight worsted suiting fabrics. Indian Journal of Fibre \& Textile Research, 2007;32:319-325.

6. Xu G, Wang F. Prediction of the shearing hysteresis of worsted fabrics. The Journal of The Textile Institute, 2009;100(8):709-714.

7. Kim HA, Kim SJ. Mechanical properties of worsted fabrics for emotional garment to the rapier loom characteristics. Fibers and Polymers, 2013;14(12):21632168.

8. Shahabi NE, Saharkhiz S, Varkiyani H, Mohammad S. Effect of fabric structure and weft density on the poisson's ratio of worsted fabric. Journal of Engineered Fabrics \& Fibers, 2013;8(2):63-71.

9. Mert E, Oğlakcioğlu N, Bal Ş, Marmarali A. Effects of calendering and milling processes on clothing comfort properties of suit fabrics. Journal of Textile \& Apparel/Tekstil ve Konfeksiyon, 2014;24(2):212-218.

10. Farahani MK, Shaikhzadeh Najar S, Haghpanahi M, Bameni Moghadam M. Modeling the bagging behavior of worsted fabrics using response surface methodology. The Journal of The Textile Institute, 2018;109(5):695-702.

11. Ozdemir H. Air permability of worsted fabrics. Industria Textila, 2018; 69(4):322-327.

12. Akcagun $\mathrm{H}$, Bączek MG, Hes L. Thermal insulation and thermal contact properties of wool and wool/PES fabrics in wet state. Journal of Natural Fibers, 2019;16:2,199-208.

13. Mousazadegan F, Ezazshahabi N. Contribution of constituent yarns of the worsted woven fabrics in various directions during the tensile loading. Journal of Engineered Fibers and Fabrics, 2019;14:1-10.

14. Oner E, Okur A. Thermophysiological comfort properties of selected knitted fabrics and design of T-shirts. The Journal of The Textile Institute, 2015; 106(12):1403-1414.

15. Saville BP. Physical testing of textiles. Cambridge: Woodhead; 1999. 
16. Gundogan K., Koksal D. Nanopartikül takviyeli polimer matrisli r-pet geri dönüşüm ipliklerinin mikroyapı, termal, mekanik ve antistatik özelliklerinin incelenmesi. Gümüşhane Üniversitesi Fen Bilimleri Enstitüsü Dergisi; 2020; 10(3):526-534. 